\title{
Miíase labial: relato de caso clínico
}

\section{Labial myiasis: clinical case report}

\section{Miiasis labial: reporte de caso clínico}

\begin{abstract}
Resumo
Mí́ase é uma doença definida como uma invasão dos tecidos vivos ou mortos de um hospedeiro humano ou animal vertebrado, por ovos ou larvas de moscas da ordem díptera, podendo ser classificada com base na área do corpo acometida, sendo uma destas a miíase oral, condição a qual pode se manifestar em diversas localizações dentro da cavidade oral. O profissional cirurgião-dentista necessita estar atento à casos de míáase na cavidade oral envolvendo adultos e crianças, realizando o diagnóstico precoce e atendimento imediato. Objetivou-se descrever a clínica de um caso raro de miíase labial de uma vítima de agressão e encarceramento, desde seu diagnóstico, tratamento emergencial e a resolução do caso. $\mathrm{O}$ acometimento de mí́ase na região oral e maxilofacial é uma ocorrência rara, que pode acarretar em extensas sequelas para o indivíduo e seu prognóstico está diretamente relacionado com o tempo, o local de ocorrência e as condições sistêmicas do paciente. O profissional cirurgião-dentista necessita estar atento para intervir de forma rápida e precisa, reduzindo assim agravos e danos decorrentes bem como uma rápida e melhor recuperação do paciente.
\end{abstract}

Palavras-chave: Infestações por larvas das moscas; Ferimentos e lesões; Lesão labial; Papel do bucomaxilo.

\begin{abstract}
Myiasis is a disease defined as an invasion of living or dead tissues of a human or vertebrate animal host by the eggs or larvae of flies of the order Diptera, which can be classified based on the area of the body affected, one of which is oral myiasis, a condition which can be manifested in several locations within the oral cavity. the dental surgeon needs to be aware of cases of myiasis in the oral cavity involving adults and children, making an early diagnosis and immediate care. The objective was to describe the clinic of a rare case of labial myiasis in a victim of aggression and imprisonment, from its diagnosis, emergency treatment and resolution of the case. The involvement of myiasis in the oral and maxillofacial region is a rare occurrence, which can cause extensive sequelae for the individual and its prognosis is directly related to the time, place of occurrence and the patient's systemic conditions. The dental surgeon needs to be aware to intervene quickly and accurately, thus reducing injuries and resulting damage as well as a quick and better recovery of the patient.
\end{abstract}

Keywords: Fly larva infestations; Wounds and injuries; Lip lesion; Role of the maxillary mouth.

\section{Resumen}

La miasis es una enfermedad definida como la invasión de tejidos vivos o muertos de un huésped humano o animal vertebrado por los huevos o larvas de moscas del orden Diptera, que pueden clasificarse en función del área del cuerpo afectada, una de las cuales es la miasis oral, una afección que puede manifestarse en varios lugares dentro de la cavidad bucal. El cirujano dentista debe conocer los casos de miasis en la cavidad bucal que involucran a adultos y niños, realizando un diagnóstico precoz y atención inmediata. El objetivo fue describir la clínica de un caso raro de miasis labial en una víctima de agresión y encarcelamiento, desde su diagnóstico, tratamiento de emergencia y resolución del caso. La afectación de la miasis en la región oral y maxilofacial es una ocurrencia rara, que puede causar extensas secuelas para el individuo y su pronóstico está directamente relacionado con el momento, lugar de ocurrencia y condiciones sistémicas del paciente. El cirujano dentista debe ser consciente para intervenir con rapidez y precisión, reduciendo así las lesiones y los daños resultantes, así como una rápida y mejor recuperación del paciente.

Palabras clave: Infestaciones por larvas de moscas; Heridas y heridas; Lesión de labio; Papel de la boca maxilar. 


\section{Introdução}

Miíase é um termo derivado do grego Myia que significa mosca e Ase que significa doença, sendo portanto de forma geral definido, como uma invasão dos tecidos vivos ou mortos de um hospedeiro humano ou animal vertebrado, por ovos ou larvas de moscas da ordem díptera, popularmente conhecida como "berne" e "bicheira", embora sejam causada por invasores diferentes (Costa-Júnior, 2019; Queiroz et al., 2019), a bicheira é provocada pela mosca varejeira uma mosca grande e esverdeada (Cochliomyia hominivorax) e a berne pela mosca comum (Dermatobia hominis) (Martins, 2018). Sua presença no ser humano está associada a práticas insatisfatórias de hábitos de higiene e condições sanitárias; sendo sua manifestação comumente presente em pele com lesões ulceradas (Boros et al., 2006; Theotonio et al., 2017).

Em geral a doença é comum principalmente em áreas tropicais e possui fácil diagnóstico, devido sua manifestação clínica, a partir do desenvolvimento da larva, ocorre a formação de um nódulo no local, com um aspecto menos inflamatório do que um furúnculo, estando na parte central do nódulo um orifício, que pode apresentar serosidade e quando a larva atinge a maioridade, começa se mover, causando a dilatação e abertura pela qual ela sai, com posterior cicatrização da lesão. (Melo et al., 2003; Henrique et al., 2020).

O agente etiológico de maior incidência na pele humana é o Cochliomyia hominivorax (Santos et al., 2021). A miíase pode ser classificada com base na área do corpo acometida. Estando dentre estes a miíase oral, condição a qual pode se manifestar em diversas localizações dentro da cavidade oral como em bolsas periodontais, feridas resultantes de exodontias e feridas abertas em geral (Cavalcanti, 2008).

O tratamento convencional ocorre por meio da remoção mecânica das larvas, com o auxílio da cureta periodontal e pinça clínica, por meio de anestesia local (Theotonio et al., 2017).

Embora profissionais médicos otorrinolaringologistas e dermatologistas, possuam maior vivência com esta patologia o profissional cirurgião-dentista necessita estar atento à casos de miíase na cavidade oral envolvendo adultos e crianças, realizando o diagnóstico precoce e atendimento imediato, com o objetivo de reduzir agravos e danos decorrentes dessa patologia e assim proporcionando uma rápida e melhor recuperação do indivíduo (Junior et al., 2019). O objetivo do presente estudo foi descrever a clínica de um caso raro de miíase labial de uma vítima de agressão e encarceramento, desde do diagnóstico, tratamento emergencial até a resolução do caso.

\section{Metodologia}

Relato de caso do tipo descritivo de caráter narrativo e reflexivo (Silva-Souza et al., 2021). Realizado no Hospital Regional de Cáceres Antônio Fontes (HRCAF) em Cáceres-MT no ano de 2021. A cidade de Cáceres é polo regional de saúde da região oeste, sendo referência para o atendimento de 22 munícipios, tem uma população de aproximadamente de 90 mil habitantes e IDHM de 0,71 (IBGE, 2021).

O HRCAF é um hospital da região que oferece atendimento secundário e terciário, dentre as especialidades oferece o serviço de cirurgia e traumatologia bucomaxilofacial (CNES, 2021).

O caso foi acompanhado entre os meses de fevereiro a junho de 2021.

O relato foi aprovado pelo comitê de ética em pesquisa da Faculdade São Leopoldo Mandic sob parecer n 4.726.698.

\section{Relato do Caso}

Paciente sexo masculino, cor da pele branca, 36 anos, trabalhador rural, trazido ao serviço de emergência do Hospital Regional de Cáceres Antônio Fontes (HRCAF) pelo serviço de resgate do corpo de bombeiros de Cáceres-MT, em 07 de fevereiro de 2021. Vítima de espancamento, imobilizado e mantido em cativeiro por três dias em local ermo. 
Paciente deu entrada no hospital, consciente, orientado, agitado, relatando dor intensa, apresentando lesão extensa no lábio inferior do lado esquerdo, coloração escurecida caracterizando necrose, presença de larvas preenchendo toda extensão da lesão, odor fétido, lábio superior edemaciado (Figura 1A).

Paciente atendido inicialmente pelo serviço de cirurgia geral que após avaliação e conduta foi dado alta da especialidade e transferido ao serviço de cirurgia e traumatologia bucomaxilofaciais, ao qual ficou sob cuidados. Feito internação, comunicado centro cirúrgico da necessidade do atendimento emergencial sob anestesia geral. Solicitados exames laboratoriais, iniciado tratamento terapêutico com prescrição de: Clindamicina 600mg (EV) 8/8hs, Tenoxican 20mg (EV) 12/12hs, Tramadol 50mg (EV) 8/8hs, Soro glicosado 10\% 1000ml (EV).

Figura 1. Entrada na emergência do HRCAF, paciente apresentando necrose no lábio inferior com presença de larvas (A); atendimento no centro cirúrgico sob anestesia geral (B), Cáceres-MT, Brasil, 2021.
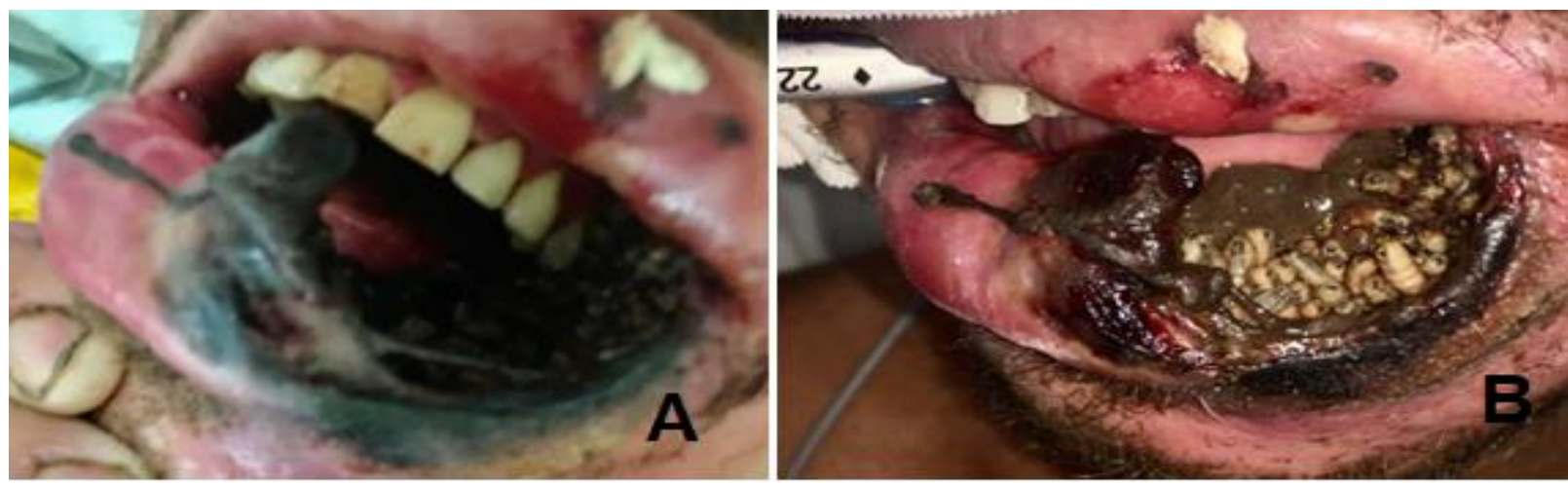

Fonte: Elaborado pelos autores em 07/02/2021.

Avaliados exames laboratoriais, paciente encaminhado ao centro cirúrgico. Após avaliação da anestesiologia, optou-se por anestesia geral com intubação via oral (Figura 1B).

Paciente em decúbito dorsal, antissepsia intra e extra oral com clorexidina sabão 4\% (Figura 2A), aposição de campo cirúrgico, remoção mecânica das larvas, anestesia local em fundo de vestíbulo com mepivacaina 2\% com epinefrina 1:100.000, remoção de tecido necrótico e desbridamento, presença de inúmeros túneis na base da lesão (Figura 2B) onde foi mantido uma pasta de iodofórmio mais vaselina e tamponada com gases (fixada com fio de nylon), mantido tamponamento para remover larvas remanescentes (Figura 3A), após recuperação pós anestesia, paciente encaminhado para a clínica, liberado dieta leve e antissepsia com clorexidina $0,12 \%$. 
Figura 2. Antissepsia intra e extra oral (A); Remoção de tecido necrosado e debridamento (B), Cáceres-MT, Brasil, 2021.
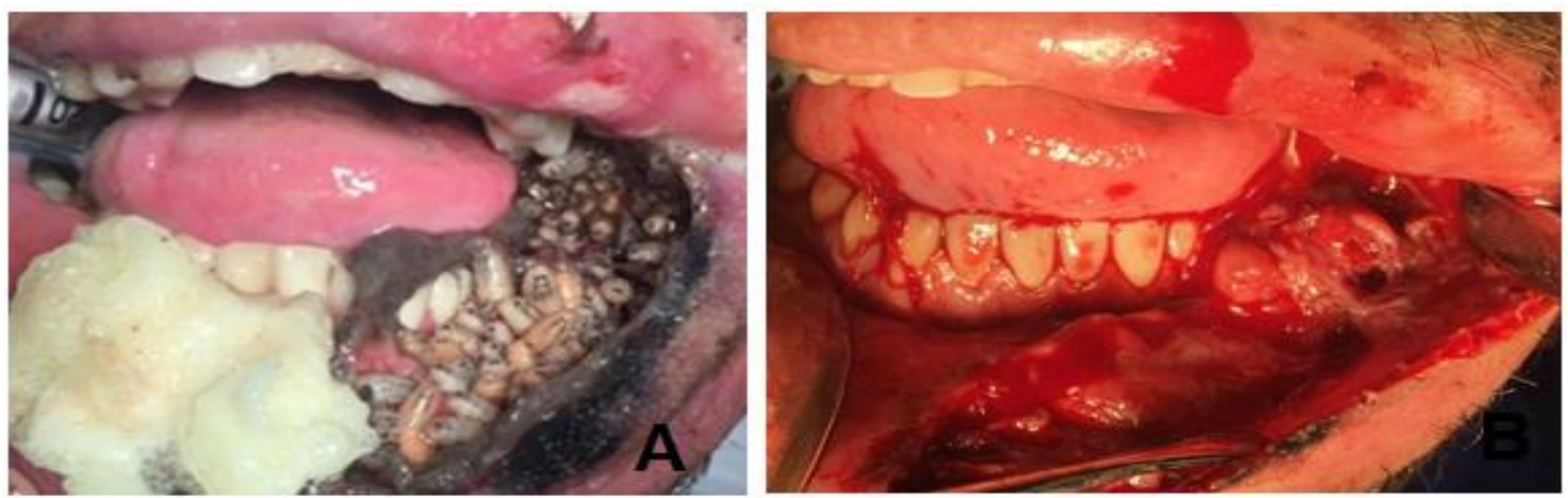

Fonte: Elaborado pelos autores em 07/02/2021.

Após 12 horas nova abordagem, removido tamponamento, feito antissepsia intra e extra oral, anestesia infiltrativa local em fundo de vestíbulo com mepivacaína 2\% com epinefrina 1:100.000, lesão irrigada com soro fisiológico $0,9 \%$, removida mais 15 larvas, exploração visual dos túneis, promovido leve desbridamento e sutura com fio vicril 5.0 (Figura 3B), paciente liberado para a clínica ficando em observação por mais $12 \mathrm{hs}$, recebendo alta e programado retorno ambulatorial.

Figura 3. Tamponamento para acomodar iodofórmio mais vaselina (A); Remoção do tamponamento e das larvas remanescentes (B); curativo (C), Cáceres-MT, Brasil-MT, 2021.
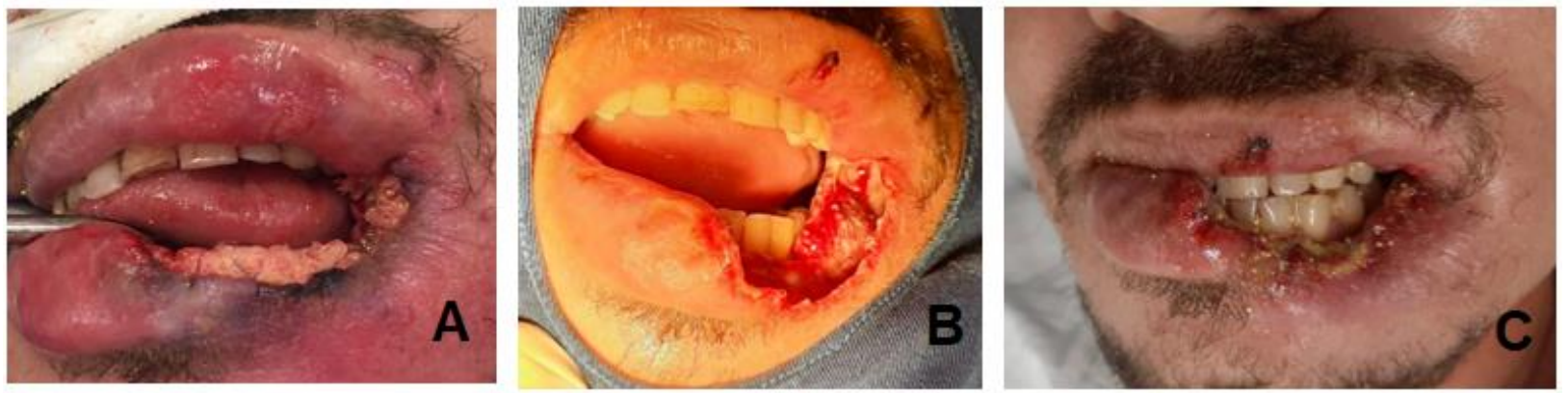

Fonte: Elaborado pelos autores em 07/02/2021 (A) em 08/02/2021 (B e C).

O retorno do paciente aconteceu após quatro meses e treze dias da alta hospitalar, em 23 de junho de 2021, observou que após cuidados locais, apresentava bom aspecto de cicatrização, mas com perda parcial do lábio inferior do lado esquerdo (Figura 4). Foi solicitado outro retorno onde será feito encaminhamento para a Cirurgia Plástica.

Figura 4. Retorno pós operatório, Cáceres-MT, Brasil, 2021.
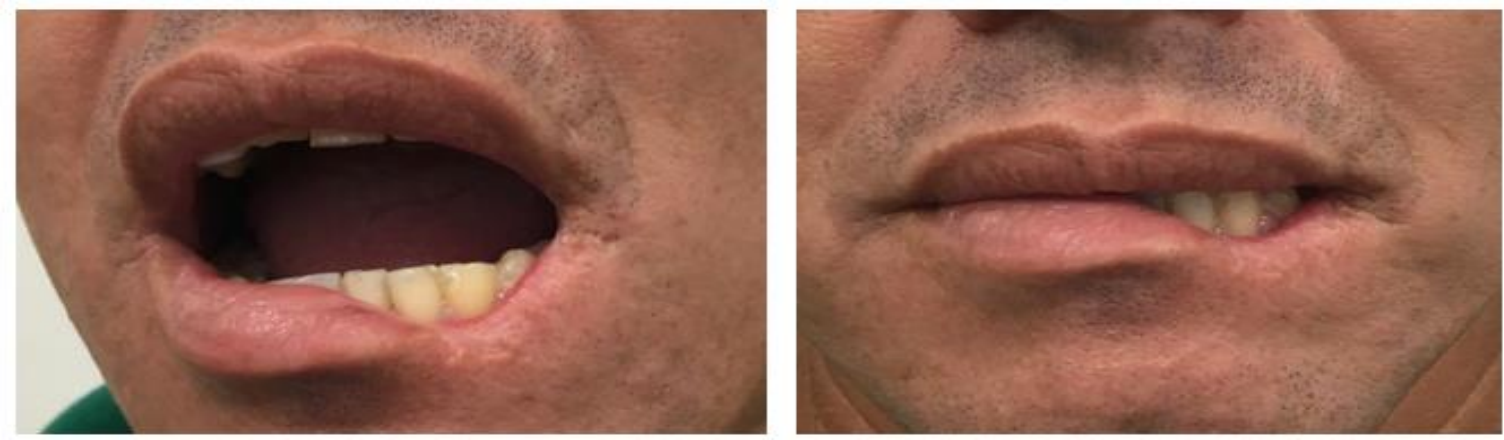

Fonte: Elaborado pelos autores em 23/06/2021. 


\section{Discussão}

Devido a localização é raro o desenvolvimento da miíase oral em pessoas sadias, isto por que no caso de infestação a maturação das larvas causa inflamação do tecido e o desconforto causado leva o indivíduo a procurar o atendimento médico o mais rápido possível (Da Silva et al., 2009). O caso relatado foi ocasionado por situação atípica, e o progresso da doença foi favorecido devido a impossibilidade de movimentação do indivíduo e cuidados com as lesões, o que ocasionou perda parcial do tecido labial.

A miíase oral está geralmente relacionada as lesões pré-existentes como cortes contusos (Lucena et al., 2020), maus tratos/ abandono ou descuidos com a higiene (Pereira Junior et., 2019; Sampaio et al., 2021), os casos relatados nesse local são incomuns comparado a outros locais do corpo, neste caso ocorreu ferimento na região oral pelo espancamento e como o indivíduo estava amarrado, alguma mosca tenha então depositado seus ovos no local.

No caso relatado não foi possível investigar a espécie das larvas causadora da lesão, mas pelas características apresentadas é provável que sejam miíase do tipo obrigatória que é causada pela única mosca da família Calliphorina da espécie Cochliomyia hominivorax, nessa espécie as larvas se alimentam de tecidos vivos, a mosca pousa na pele ferida e coloca de 200 a 300 ovos que em 24 horas se transformam em larvas e destroem os tecidos pelos seus ganchos orais e pela liberação de enzimas proteolíticas (Linhares, 2000; Costa-Júnior, 2019).

O primeiro tratamento escolhido no caso foi a retirada das larvas mecanicamente, técnica essa que foi relatada como principal tratamento para miíase (Solomon et al., 2016; Bernhardt et al., 2019; Centers For Disease Control and Prevention, 2020).

Neste caso para morte das larvas remanescentes optou-se pelo uso de pasta de iodofórmio mais vaselina no local da infestação, esse tipo de tratamento é usado para forçar a saída ou matar a as larvas (Bhatt \& Jayakrishnan, 2000; Khan et al., 2018). O uso do iodofórmio também foi utilizado em caso relatado de mí́ase otológica na cidade de Sorocaba, São Paulo (Ruiz; Borges \& Jorge Júnior, 2019) e em outro relato de míiase no lábio superior, os profissionais também optaram pelo uso de iodofórmio após a retirada das larvas (Da Silva et al., 2009). O iodofórmio é um medicamento com ação analgésica por apresentar analogia clínica com o clorofórmio, tem ação antissifilítica, por sua relação aos iodetos; e ação antisséptica, pela presença de iodo em sua composição, ajudando a complementar a ação de desinfecção do local onde é aplicado, esse medicamento é muito utilizado na odontologia (Alvares \& Alvares Junior, 2009).

Pereira Junior et al. (2019) e Lucena et al. (2020) recomendaram após análise de casos de miíase maxilofacial a combinação da técnica mecânica de retirada de larvas com a administração de antiparasitário via oral para morte das larvas remanescentes, como um protocolo com bons resultados, já que não existe protocolo padrão para o tratamento da miíase (Lucena et al., 2020).

Para o tratamento da lesão necrótica foi realizado o desbridamento do tecido, procedimento que é aconselhável e necessário nesse caso (Chan et al., 2005). Associado ao tratamento direto para mí́ase foi administrado antibióticos e antiinflamatórios e ainda medicação para analgesia para colaborar no processo de cicatrização da lesão e diminuir as dores apresentadas. Em lesões com miíase o uso de medicamentos complementares é necessário para controle de infecção secundárias (Costa et al., 2012; Pereira Junior et al., 2019).

Complicações da miíase oral já foram relatadas por outros autores, sendo esse local do corpo favorável a complicações devido as características da mucosa e pele (Da Silva et al., 2009; Henrique et al., 2020).

Da Silva et al. (2009) referem que a cicatrização pós tratamento de miíase pode ser completa. Neste relato de caso a cicatrização apresentou perda de tecido labial com comprometimento estético, este fato está relacionado as condições que geraram a lesão, como o paciente ficou impossibilitado de procurar ajuda onde aconteceu o agravamento da lesão e perda do tecido devido a grande quantidade de tecido necrosado. Outro caso relatado em Jales - São Paulo, o paciente recebeu o 
tratamento, porém devido à falta de cuidado do próprio paciente não houve cicatrização completa e após seis meses a região afetada pela míiase apresentou comprometimento estético e funcional do lábio superior (Da Silva et al., 2009).

Os profissionais de saúde não devem esquecer que as infestações por miíase são de grande importância para a saúde pública e geralmente indica problemas relacionados a falta de higiene e as condições de moradia dos portadores, embora no caso exposto seja uma rara infestação, no dia a dia o profissional deve estar atento e conhecer suas características e as técnicas para o tratamento (Santos, 2012; Sampaio; De Oliveira \& Menezes, 2021). Embora seja rara a infestação na região oral, os profissionais da saúde, precisam estar atentos as características apresentadas na míase para intervenção rápida e eficaz que irá garantir uma recuperação completa ao paciente.

\section{Conclusão}

O acometimento de miíase na região oral e maxilofacial é uma ocorrência rara, que pode acarretar em extensas sequelas para o indivíduo e seu prognóstico está diretamente relacionado com o tempo, o local de ocorrência e as condições sistêmicas do paciente. O profissional cirurgião-dentista necessita estar atento à casos de miíase na cavidade oral para intervir de forma rápida e precisa, reduzindo assim agravos e danos decorrentes bem como uma rápida e melhor recuperação do paciente.

\section{Referências}

Alvares, D. C., \& Alvares Junior, J. C. (2009). Endotoxina na Endodontia. Ver Cient UFPA, 7(1):8-17.

Bernhardt, V., Finkelmeier, F., Verhoff, M. A., \& Amendt, J. (2019). Myiasis in humans-a global case report evaluation and literature analysis. Parasitol Res, 118(2):389-97.

Bhatt, A. P, \& Jayakrishnan, A. (2000). Oral myiasis: a case report. Int J Paediatr Dent., 10:67-70.

Boros, L. F., \& et al. (2006). Miíase labial. DENS, 14(1).

Cavalcanti, A. L. (2008). Míase Oral: etiologia, diagnóstico e tratamento. Revista da Faculdade de Odontologia de Porto Alegre, 49(2), 3235 .

Centers for Disease Control and Prevention. Parasites Home. (2021) Myiasis. Resources for health professionals. https://www.cdc.gov/parasites/myiasis/health_professionals/index.html.

Chan, T., Yan, K., Yien, L., \& Yuen, W. (2005). Oral and cutaneous myiasis caused by Chrysoma bezziana. Ann Coll Surg Hong Kong, 9:28-30.

CNES. Cadastro Nacional de Estabelecimentos de Saúde. Estabelecimentos de saúde de Cáceres-MT. http://cnes2.datasus.gov.br/Lista_Es_Municipio.asp?VEstado=51\&VCodMunicipio=510250\&NomeEstado=MATO

Costa, F. S., Bellotti, A., Farah, G. J., \& Camarini, T. (2012). Hipertratamento de miíase decorrente de trauma facial complexo. Rev. Cir. Traumatol. Buco-Maxilo-Fac., 12:17-24.

Costa-Júnior, L. M., Chaves, D. P., Brito, D. R. B., Santos, V. A. F., Costa-Júnior, H. N., Barros, A. T. M. (2019). Rev. Bras. Parasitol.

Da Silva, P. R. F., Yoshida, L., \& Soares, L. E. S. (2009). Miíase em paciente não colaborador: relato de caso clínico. XIII Encontro Latino Americano de Iniciação Científica e IX Encontro Latino Americano de Pós-Graduação - Universidade do Vale do Paraíba.

Henrique, M. M., \& et al. (2020). Miíase Furuncular: Relato de caso. Brazilian Journal of Development, 6(8), 62684-62691.

IBGE. Instituto Brasileiro de Geografia e Estatística. Cidades: Cáceres-MT. https://cidades.ibge.gov.br/brasil/mt/caceres

Júnior, A. J. A. P., \& et al. (2019). Miíase maxilofacial: relato de casos. HU Revista, 45(1), 76-81.

Khan, B. A., Nazir, M. B., Perveen, B., \& Bin, M. (2018). Oral and cutaneous myiasis in a five-year-old child from Karachi, Pakistan. Infez Med., 1:385-8.

Linhares, A. X. . (2000). Miíases. In: Neves, D.P. Parasitologia Humana. 10. Ed, Atheneu, 350-8. 
Martins, L. G. V. (2018). Identificação de casos de miíases em pacientes de unidades de saúde de Natal/RN. Dissertação (Mestrado em CiênciasBiológicas) - Centro de Biociências, Universidade Federal do Rio Grande do Norte, Natal.

Melo, R. E. V. A., \& et al. (2003). Miíases No Lábio Superior-Apresentação De Caso Clínico. International Journal of Dentistry, 2(1), 221226.

Queiroz, M. M. C., Duarte, M. L., Braga, M. V., \& Cortinhas, L. B. (2019). Identificação das espécies causadoras de miíases em humanos provenientes dos serviços de saúde do município de Nova Iguaçu, RJ, entre os anos de 2017 e 2018. Revista em Saúde.

Ruiz, H. T., Borges, G. C., \& Jorge Júnior, J. J. (2019). Miíase otológica. Revista Da Faculdade De Ciências Médicas De Sorocaba, 20(4), 238-240. https://doi.org/10.23925/1984-4840.2018v20i4a11

Sampaio, A. T. P., de Oliveira, E. S., \& Menezes, M. R. S. (2021). Assistência de enfermagem em miíase humana para pessoas em situação de rua: revisão integrativa da literatura. Revista JRG de estudos acadêmicos, IV(IV):8.

Santos, T. L., Narciso, A. G., Souza, J. V. F. de, Rocha, T. S., \& Bastos, L. R. (2021). Incidência de complicações decorrentes de infestação por miíase: uma revisão bibliográfica. REMS, 2(1):32.

Silva, M. C., de Lima Neto, T. J., de Souza Santos, A. M., Faverani, L. P., Inaoka, S. D., \& da Costa, D. F. N. (2021). Cisto ósseo traumático em área incomum: relato de caso. Archives of health investigation, 10(1), 170-173.

Solomon, M., Lachish, T., \& Schwartz, E. (2016). Cutaneous myiasis. Curr Infect Dis Rep., 18(9):28.

Theotonio, J. A., \& De Brito Resende, Â. F. (2017). Óbito decorrente de míase em regiao maxilofacial: Relato de caso clínico. Rev. Cir. traumatol. Buco-MaxiloFac, 17, 27-31. 